\title{
Using Process Evaluation To Promote Students'Inventive Ability Devel- opment - Taking Tourism Aesthetics As An Example
}

\author{
Lin Zeng \\ Shanghai Institute of Tourism, Shanghai, 200092
}

\begin{abstract}
: with the rapid development of tourism industry, it requires more and more high quality of tourism practitioners, therefore, colleges and universities are particularly important to the cultivation of high-quality tourism practitioners. Tourism Aesthetics is one of the important courses of tourism management and hotel management in colleges and universities. Aiming at the present situation and existing problems of tourism aesthetics course, this paper evaluates the cultivation of students'innovation ability by process, studies and discusses the reform of tourism aesthetics course teaching from 3 aspects: school, teachers and students.
\end{abstract}

Keywords: Process evaluation Innovation capacity Cultivation of Tourism Aesthetics

DOI: 10.36012 /fhe.v1i2.1436

$\mathrm{T}$

ourism aesthetics is a professional course for students majoring in tourism and hotel management. It takes tourism aesthetic object (that is, tourist's viewing object), tourism aesthetic subject (that is, tourist) and many aesthetic relations in tourism, especially the relationship between people as the aesthetic branch of its research object. Because tourism is a kind of social practice activity, which is closely related to material production and various economic sectors, tourism aesthetics is not only different from general aesthetic principles, but also different from other branches of aesthetics, such as painting aesthetics, music aesthetics, poetry beauty, which has its own unique system theory, and it also has strong practicality and maneuverability. The orientation of innovation ability training is an important part of the education of students majoring in tourism and hotel. The orientation of innovation ability training needs teachers to be able to cultivate students'innovative ability as the leading thought in teaching activities, and permeate this idea into the whole process of teaching.

\section{Problems in the Teaching of Tourism Aes- thetics}

\subsection{Teaching Content Ignores the Cultivation of Students' Innovation Ability}

At present, the teaching contents of "tourism aesthetics" mainly include: aesthetic object (natural landscape and human landscape) aesthetic characteristics appreciation, aesthetic subject (tourist) aesthetic psychological process, tourism aesthetics related principles and aesthetic requirements of tourism workers. Moreover, basically take the aesthetic object aesthetic characteristic appreciation as the main body of the explanation content, the result of overemphasising the application of knowledge and neglecting the theoretical basis is often "the students' thinking is simple, lack of innovation, after work sensory is useless, lack of development stamina " [1]. Therefore, at present, the teaching content of "Tourism Aesthetics" basically ignores the cultivation of students' innovative ability.

2.2 The lack of practical teaching is not conducive to the cultivation of students' innovative ability Considering the safety of students, the convenience of school teaching management and the difficulty of guaranteeing funds, the teaching of tourism aesthetics in some colleges and universities is basically completed in the classroom, and there are few on-site practice teaching, which makes the teaching effect of tourism aesthetics poor, let alone cultivate students' aesthetic observation, understanding and innovation ability in practical teaching.

2.3 The teaching mode is not suitable for the cultivation of students' innovative ability

At present, most teachers adopt the teaching mode of "teacher speaking, student listening" in the class of "tourism aesthetics ", the teaching time of teachers is mainly based on theory, the landscape appreciation mainly depends on a few pictures or short video, such class is relatively boring, it is difficult to arouse students'interest, let alone guide students to explore the landscape actively; in teaching means, although teach- 
ers make PPT, they are limit ed by the teaching resources (multimedia teaching equipment behind the blurred picture) and the school teaching management system (such as some colleges and universities do not allow teachers to play video in the teaching process, or have strict regulations on the length of video, etc.), the teaching effect is not good, and students do not adapt to the cultivation of innovative ability.

2.4 The lack of aesthetic practice of teacehers is not conducive to the cultivation of students'innovative ability

Although some "tourism aesthetics" teachers have a relatively perfect aesthetic knowledge system, aesthetic practice is relatively lacking, in the analysis of the characteristics of landscape aesthetics can only talk on paper, neither really from the aesthetic experience of tourists, nor from the tourism practitioners to provide aesthetic services to tourists. Therefore, it is more difficult for teachers to improve students' aesthetic appreciation under the background of learning characteristics, and it is more difficult to improve students' aesthetic accomplishment from the perspective of innovation.

2.5 Students' innovation consciousness is not strong enough to hinder the cultivation of students' innovation ability

Teaching and learning are long-term, but at present, more and more students in colleges and universities do not pay attention to active exploration, basically in a passive state of "want me to learn ", do not pay attention to the cultivation of their own innovation consciousness and innovation ability, the same is true of the course of tourism aesthetics, such as analyzing the characteristics of a certain landscape aesthetics, mechanical copy of teaching materials or network materials, rarely explore actively.

2.6 Evaluation of course assessment is not conducive to the cultivation of students' innovative ability

When most colleges and universities evaluate the tourism aesthetics, they still adopt the traditional assessment mode, that is," one test paper decides to win or lose ". Such an assessment method only requires students to memorize the teaching materials by rote, and it is difficult to reflect the students' practical ability to use the aesthetic knowledge they have learned, not to mention how to assess the students' innovative ability in appreciating the characteristics of landscape aesthetics.

\section{Using Process Evaluation to Promote the Teaching Reform of Tourism Aesthetics}

\subsection{Design and Implementation of Process Evalua-} tion

The process evaluation design of the tourism aesthetics course draws on the evaluation method of the Australian scholar Biggs ${ }^{[2]}$, and explores the process evaluation model based on innovation training ability based on the relevant factors such as teaching situation and learning situation (Fig.1) .

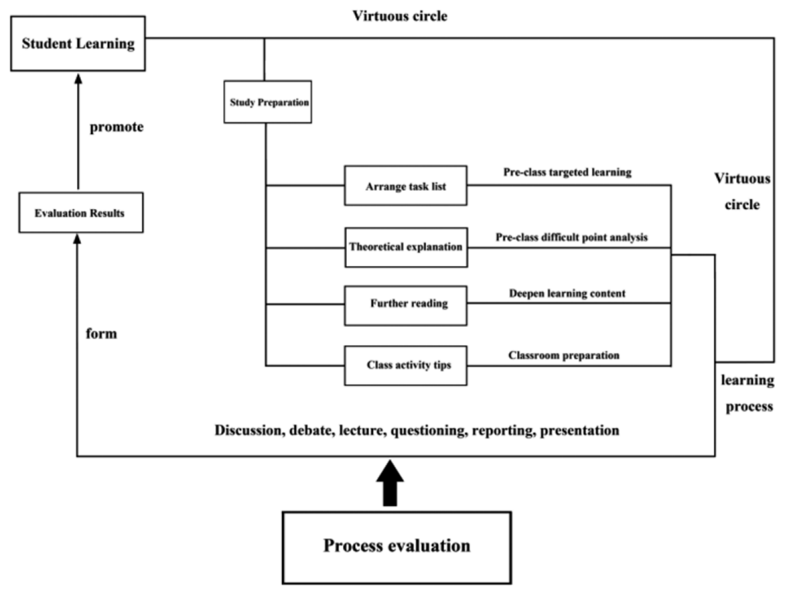

Figure 1. Process evaluation model

Process evaluation is not only a requirement for students to learn, but also a challenge for teachers to organize the classroom, but also a transformation of teaching methods. "Tourism Aesthetics" process evaluation from learning preparation to classroom learning, and then to form evaluation results, the whole process focuses on the examination of students' self-learning ability. In the preparatory stage of learning: first of all, to issue a study task list to the students, to clarify the task of autonomous learning; second, to analyze the key points and difficulties of the course; third, to provide expanded reading materials through video to assist, consolidate and deepen the learning content; fourth, to stimulate the students'imagination of the course through "classroom activity tips ", and to guide the students'thoughts from the pre-class to the class. In the classroom learning stage: combine with the content of the preparatory stage of learning, flexible use of explanation, discussion, debate, speech, questions and other forms, student-centered organization of classroom learning, guide and inspire students to complete the course learning tasks. In the process of organizing 
teaching, according to the students'classroom performance and the completion of homework after class, the individualized evaluation results of students' learning are formed. The whole evaluation is linked with the teaching link, which constitutes the interactive process of "evaluating by learning" and "promoting learning by evaluation" in a virtuous circle, so as to improve the students'learning effect.

\subsection{Refinement and Reform of Process Assessment}

Tourism Aesthetics is a practical course, therefore, teachers should reform the assessment system and methods in the course assessment, change the commonly used way to determine the results of a test paper, using the usual performance $(20 \%)$, stage evaluation (20\%), final evaluation (60\%) three links evaluation. Usually performance includes attendance, learning attitude, class participation, homework completion and so on. If the course can be designed a series of class activities: first," each class good words "activities. Each class shares famous sayings about beauty or tourism aesthetic, students choose to participate voluntarily, participants in the usual results of the additional points; second, debate activities. A debate contest on whether beauty is objective or subjective was organized, in which each of the eight study groups selected a representative to participate, and four students formed a debater to rate the group according to the performance of each student in the debate; third, the speech activities. Organized the "beauty in my eyes" speech activity, the student voluntarily chooses to participate, the participant in the peacetime achievement separately points. In this stage, pay attention to students'emotional motivation, learning attitude \& learning style according to the usual performance evaluation.

The stage evaluation is divided into two parts: one is a project operation with a group as the unit, such as arranging the project work around the western architectural aesthetic, the Chinese plastic arts aesthetic, the dress folk custom aesthetic and so on content, according to the work completion situation score appraisal; the other is the individual creative planning work, such as arranged the "garden aesthetics research course design" assignment, according to the plan content and the PPT display situation score appraisal. In the stage evaluation link, students are required to conduct mutual evaluation, and feedback evaluation is formed between groups to improve students' learning effect in interaction.

The final evaluation is open homework, around the aesthetic feeling in tourism or the feeling after reading the related books of tourism aesthetics, write an article, which requires standard format, clear logic, beautiful speech, rich feelings. The final evaluation stage is a continuous result of the whole course, therefore, the final evaluation focuses on examining the students' holistic cognition of tourism aesthetics, expressing their own opinions from the perspective of inner truth, and improving students' ability to apply knowledge comprehensively in the open guidance.

\subsection{Effect of process evaluation}

In the process of carrying out the process evaluation, it is easy to appear two tendencies, either pay too much attention to the intelligence factor, or pay too much attention to the non-intelligence factor. Although there is such a bias, the process evaluation is still a certain advantage of the evaluation. Based on the process evaluation efforts to overcome these two tendencies, through the interaction of teaching and evaluation, the goal and value of equal emphasis, in the "Tourism Aesthetics" curriculum reform practice has achieved good teaching results. First, improve the enthusiasm of students to learn. The "Tourism Aesthetics" course aims at the process evaluation of many links and stages connecting each other before, during, after and at the end of class, and carries out a comprehensive assessment of students' ability to remember, understand, express, innovate and practice. Process evaluation exerts the effect of "promoting learning by evaluation ", stimulates students' interest in learning, arouses students' enthusiasm to participate in activities, and improves students' autonomy in learning before as well as after class $^{[3]}$. Second, cultivate students' continuous learning habits. The "tourism aesthetics" uses the process evaluation model to avoid the traditional evaluation of irregular, a fixed tone or intermittent, through the whole process of learning evaluation promotes the students'continuous learning, and changes the students' previous bad habits of simply coping with the examination. From external supervision to self-discipline, students consciously develop a good habit of continuous learning. Third, dynamically grasp the students'learning situation. The course of "tourism aesthetics" adopts the flexible assessment method of "learning" and "evaluating" interaction to guide students to speak freely in class, to express their views on 
knowledge, the cognition of practice and the confusion of learning, to grasp the students' learning progress and effect in time, and to grasp the process of improving students' comprehensive ability dynamically. Fourth, promote the interaction between teachers and students. In addition to the questions and speeches in the course, the tourism aesthetics course arranges the study tasks ahead of time, examines the students' self-study before class and the class performance in the classroom, through"one-to-one","one-to-many "," many-to-many" and so on many kinds of interaction modes, has produced the good interaction between students and students, students and teachers. ${ }^{[4]}$

\section{Promote the innovation ability of students from the main body of teaching management}

In the main school of teaching management, we should strengthen the cultivation of teachers' aesthetic practice, encourage teachers to enter into enterprises, enrich teachers' aesthetic practice experience, improve teachers' aesthetic cultivation, and constantly enhance teachers' innovative consciousness and ability through the way of school funds support and teachers' self-financing, so as to promote students'aesthetic accomplishment and aesthetic appreciation ability from the perspective of innovation. The same school can pay attention to the construction of practical platform, through the purchase of software to the aesthetic object through the way of simulation into the classroom, let teachers in the classroom to appreciate the relevant landscape and appreciation, and require students to appreciate the multi-angle. On the other hand, through the cooperation of schools and enterprises, that is, the cooperation between schools and scenic spots, travel agencies and hotels, the school encourages students to understand the aesthetic object from an aesthetic point of view in practice.

\section{Conclusion}

The rapid development of tourism industry calls for high-quality tourism professionals with solid theoreti- cal knowledge, strong practical ability and innovative consciousness. As an important course of tourism management and hotel specialty, Tourism Aesthetics is a course with strong combination of theory and practice. The process evaluation of "Tourism Aesthetics" course is only a preliminary exploration, which needs to be further explored and studied. Based on the process evaluation teaching reform, it is expected to explore a meaningful evaluation system for cultivating students' innovative ability, and provide a new way of thinking for the reform of teaching in colleges and universities in China.

\section{References}

[1] Lihong Gu, Yuxia Li, Instructional design and analysis oriented by the cultivation of innovation ability [D].China Extracurricular Education,2014, (z1)

[2] Biggs,J. B \& B,Telfer.The Process of Learning (SecondEdition) [J].Prentice Hall of Australia, 1987:149.

[3] Yongliang Wang, Dongqing Li, Sihan Li, The effects of the motivation factors on the second language acquisition in individual differences - How to Keep students motivated [J]. News Dissemination, 2015(6):24-25.

[4] Yongliang Wang, Language acquisition under socio-cultural context - Comments on $<$ Second language interaction in different educational backgrounds [J].Research in Educational Development017 (22):2.

[5] Ye Zhang, Yaqiu Teng, Exploration of process evaluation reform based on microlecture\&flipped class -- Taking tourism aesthetics as an example[D].Home Drama,Issue 20, 2018

[6] Haili Wang, Research on the Teaching Content Integration of Tourism Aesthetics [D].Dalian, Liaoning Normal University,2008.

[7] Cai Chen, Some thoughts on the curriculum system reform of tourism management specialty (undergraduate)[]]. Tourism Tribune,2003(S1):35-37.

[8] Dezhen Yu, Tourism Aesthetics [M]. Tianjin, Nankai University Press,2012.

[9] Yanyan Zhang, Study on curriculum system of tourism management specialty from the perspective of experience [D].Dalian, Liaoning Normal University,2007.

[10] Gardner,H.Multiple Intelligence: The Theory in Practice [M].New York:Basic Books, 1993:70-89. 